\title{
Ateliê de Conversação: uma experiência da língua viva no contato com imigrantes
}

\section{Conversation Atelier: an experience of the living language in contact with immigrants}

\author{
João Ricardo Fagundes dos Santos* \\ Universidade de Passo Fundo \\ Passo Fundo, Rio Grande do Sul, Brasil. \\ Marlete Sandra Diedrich** \\ Universidade de Passo Fundo \\ Passo Fundo, Rio Grande do Sul, Brasil.
}

\begin{abstract}
Resumo: Este artigo apresenta uma ação do Grupo de Pesquisa em Processos de Interação em Discursos de Caráter Conversacional, envolvendo uma experiência de contato linguístico, por meio de práticas que visam garantir o direito à comunicação humana. O objetivo do trabalho é apresentar o projeto Ateliê de Conversação para imigrantes, o qual tem por finalidade promover, por meio da interação conversacional com alunos e professores do curso de Letras da Universidade de Passo Fundo/UPF, um tempo e um espaço de acolhida aos imigrantes vindos de diferentes países à cidade de Passo Fundo/RS. Vinculado às ações de extensão do Programa Ensino e Inovação, a proposta fundamenta-se teórica e metodologicamente em princípios da Teoria Dialógica do Discurso, do Círculo de Bakhtin (BAKHTIN; VOLOCHÍNOV, 2009), segundo a qual a relação entre os indivíduos em sociedade e a expressão de cada um por meio de palavras é de natureza social e é um puro produto da interação social. Os encontros promovidos, inspirados nos Ateliers de Conversation franceses, têm obtido resultados relevantes, revelando duas frentes significativas do contato com a diversidade linguística: os brasileiros, falantes de português, vivem a experiência real de contato com falantes de diferentes línguas, na sua grande maioria, africanas e crioulas; os imigrantes, além de terem um contato mediado e praticarem o uso da língua portuguesa com o auxílio dos professores, também participam de diferentes vivências interacionais verdadeiramente significativas para todos os envolvidos, por meio da língua viva em interação, o que é condição para a vida digna em sociedade.
\end{abstract}

Palavras-chave: Ateliê de conversação. Imigração. Língua em interação.

Abstract: This paper presents an action by the Research Group on Interaction Processes in Conversational Discourses, involving an experience of linguistic contact, through practices that aim to guarantee the right to human communication. The objective of the work is to present the Conversation Atelier to immigrants, which aims to promote, through conversational interaction with students and teachers of the Letras/UPF, a time and space for welcoming immigrants from different countries to the city of Passo Fundo/RS. Linked to the extension actions of the Teaching and Innovation Program, the proposal is theoretically and methodologically based on principles of the Dialogical Theory of Discourse, of the Circle of Bakhtin (BAKHTIN; VOLOCHÍNOV, 2009), according to which the relationship between individuals in society and expression of each one through words is of a social nature and is a pure product of social interaction. The meetings promoted, inspired by the French Ateliers de Conversation, have obtained relevant results, revealing two significant fronts of contact with linguistic diversity: Brazilians, Portuguese speakers, live the real experience of contact with

\footnotetext{
* Mestre em Letras, pela Universidade de Passo Fundo, Passo Fundo, Rio Grande do Sul, Brasil. E-mail: joao.ricardo1995@hotmail.com.

** Doutora em Estudos da Linguagem - Teorias do Texto e do Discurso, pela Universidade Federal do Rio Grande do Sul. Professora da Universidade de Passo Fundo, Passo Fundo, Rio Grande do Sul, Brasil. E-mail: marlete@upf.br.
} 
speakers of different languages, in their vast majority, African and Creole; immigrants, in addition to having mediated contact and practicing the use of the portuguese language with the help of teachers, also participate in different interactional experiences that are truly meaningful for all those involved, through the living language in interaction, which is a condition for life worthy in society.

Keywords: Conversation Atelier. Immigration. Language in interaction.

\section{INTRODUÇÃO}

Vivemos, nas últimas décadas, inúmeros fenômenos sociais que marcam o deslocamento de um grande número de pessoas para além das demarcações de suas fronteiras geográficas. Nesse contexto, como num processo inverso e, até mesmo contraditório, os fenômenos migratórios ainda são encarados com estranhamento e são considerados desafios de interação para grande parte das sociedades. No Brasil, a situação não é muito diferente. Não se trata mais apenas de uma realidade dos grandes centros, mas também de cidades do interior, as quais, cada vez mais, estão recebendo imigrantes e vivenciando particularidades geradas pelo processo de contato de grupos culturais diferentes.

A região centro-norte do Rio Grande do Sul, especificamente a cidade de Passo Fundo, nos últimos anos, tem recebido um número muito expressivo de imigrantes. Esse fenômeno, sem dúvida, afeta a sociedade de forma geral: economia, política, relações sociais, entre outros aspectos. Pesquisas da área de sociologia e história, principalmente de Tedesco e Grzybovski (2011), abordam especificamente essa dinâmica migratória no norte do Rio Grande do Sul. Nesse panorama geral, focalizamos o contexto de interação. $\mathrm{Na}$ realidade social a que nossa experiência se volta, os imigrantes falam duas ou três línguas modernas (normalmente francês, espanhol e inglês) e sua língua materna regional, a qual varia de país para país. No Brasil, eles se deparam com uma população que fala língua portuguesa, a qual, como se sabe, é diferente da versão europeia, mais difundida e conhecida para muitos. Esse encontro, na maioria das vezes, gera um conflito na interação, o que dificulta a integração dos imigrantes na nova sociedade.

São esses conflitos de interação que motivaram o projeto que será aqui apresentado. O curso de Letras e o Programa de Pós-Graduação em Letras (PPGL) da Universidade de Passo Fundo, na busca de uma integração interacional realmente significativa com os imigrantes na cidade, propõem o Ateliê de Conversação. O projeto propõe ações sistemáticas que buscam promover, por meio de encontros de interação conversacional, um tempo e um espaço de acolhida aos imigrantes que chegam à cidade de Passo Fundo. A ação é inspirada no Atelier de Conversation francês, retratado no documentário de 2018, dirigido por Bernhard Braunstein. As atividades, basicamente, envolvem professores e estudantes que recebem os imigrantes convidados para que todos possam se conhecer melhor, num processo interacional multilíngue e multicanal, no qual concorrem para o estabelecimento de sentido as construções linguísticas em português, francês, inglês, espanhol, línguas africanas e crioulas, mas também as gestualidades e os olhares.

Parte-se do princípio de que não há estrangeiros, mas pessoas que ainda não se conhecem. Dessa forma, os encontros têm o objetivo de socializar experiências pessoais 
por meio da língua viva, em interação, oportunizando o contato com diferentes línguas, em especial, a portuguesa. Para muitos imigrantes, participantes dos encontros, o Ateliê surge como a possibilidade de interagir em língua portuguesa de maneira mais confortável, diminuindo o medo de julgamento social, que sempre existe, mas, nas práticas do projeto, procura ser minimizado. A proposta fundamenta-se teórica e metodologicamente em princípios da Teoria Dialógica do Discurso, do Círculo de Bakhtin (BAKHTIN; VOLOCHÍNOV, 2009), segundo a qual a relação entre os indivíduos em sociedade e a expressão de cada um por meio de palavras é de natureza social e é um puro produto da interação social. Então, o objetivo dos encontros é interagir, compartilhar experiências e não expor a maneira de falar de cada um.

O artigo está organizado da seguinte maneira: inicialmente, apresentamos reflexões teóricas pautadas nos princípios da Teoria Dialógica do Discurso, do Círculo de Bakhtin (BAKHTIN; VOLOCHÍNOV, 2009), com o enfoque principal na concepção de interação verbal e na relação entre os indivíduos sociais e o uso da língua. Na seção seguinte, apresentamos um breve recorte sobre a dinâmica migratória no norte do Rio Grande do Sul, que instigou a investigação aqui realizada e resultou na possibilidade das ações do projeto Ateliê de Conversação para imigrantes. Depois disso, apresentamos a ideia dos encontros em forma de "Ateliê", que possui uma estrutura e finalidade própria, relevante para a área de estudos da interação. Ressaltamos o desenvolvimento de conhecimentos e saberes, resultante dos encontros, tanto para brasileiros, falantes de português, que vivem a experiência real de contato com falantes de diferentes línguas; quanto para imigrantes, que praticam o uso da língua portuguesa e também participam de diferentes vivências interacionais verdadeiramente significativas. Por fim, apresentamos algumas considerações finais sobre os resultados do projeto e sua relação com o estudo da língua viva em interação, o que é condição para a vida digna em sociedade.

\section{LINGUAGEM COMO FENÔMENO SOCIAL DE INTERAÇÃO}

Os conceitos bakhtinianos de língua e interação são base para o trabalho teóricometodológico no projeto. As ações evidenciam a língua viva na interação verbal, como um fenômeno social interativo. Sendo social, a língua, no uso cotidiano, é fortemente carregada de conteúdo ideológico, de conteúdo relativo à vida. O sentido é determinado pela realidade social e cultural, pelos envolvidos na interação e pelos efeitos que esse dito causa nas pessoas e na sociedade. São essas concepções que motivam o trabalho com língua e interação no Ateliê de Conversação, apresentado nesse trabalho.

Sem dúvida, a participação do homem em sociedade se efetiva sempre por meio da interação, constituída de elementos linguísticos, os quais estão impregnados de elementos sociais, culturais e ideológicos. Já que as interações são condicionadas pelo contexto social, a busca de sentidos se dá na relação dialógica entre o uso da língua e o contexto social da situação interacional. Para entendermos essa concepção de interação, convocamos a discussão sobre a natureza social da linguagem, proposta pelo Círculo de Bakhtin.

De início, é imprescindível salientar que o pressuposto bakhtiniano é a natureza social da linguagem. Os princípios de Mikhail Bakhtin e seu Círculo defendem a íntima 
relação entre linguagem e sociedade, ou seja, a linguagem vista como uma prática social. O sentido dos discursos cotidianos e artísticos se relaciona diretamente com a situação em que esses são produzidos. Assim, nos estudos baseados na teoria bakhtiniana, é preciso analisar a situação social, ou seja, o contexto. Volochínov (1981) apresenta a linguagem não como algo sobrenatural, invenção ou abstração, mas como um produto da atividade humana social e coletiva, da organização econômica e sociopolítica da sociedade.

Se a linguagem tem natureza social e coletiva, a língua não pode ser vista como um código abstrato, estável e uniformizador. Essa consideração mostra a relevância de um trabalho pautado na busca de interação conversacional com os imigrantes, ao invés da promoção de aulas de ensino da língua portuguesa. Apenas ensinar e praticar a língua, como código, não é significativo para os sujeitos que irão usar essa língua em situações concretas, rodeadas de elementos históricos, culturais e sociais que extrapolam o sistema linguístico. A língua, como fenômeno integral concreto, é um fenômeno socio-histórico, "[...] dura e perdura sob a forma de um processo evolutivo contínuo. Os indivíduos não recebem a língua pronta para ser usada; eles penetram na corrente da comunicação verbal" (BAKHTIN; VOLOCHÍNOV, 2009, p. 111). A língua é viva na interação verbal, portanto, apresenta-se como um fenômeno social interativo. Essa concepção é o que dá suporte ao trabalho no Ateliê, que visa não "ensinar língua", mas promover e favorecer o fenômeno social em um processo de interação linguística. Não acreditamos que haja algo de errado em se ensinar língua de maneira formal aos imigrantes, inclusive, entendemos ser necessário em muitos casos este ensino formal, mas é importante ter claro que o objetivo do Ateliê vai além disso e envolve um olhar para a língua viva, na interação.

Sendo social, a língua, no uso cotidiano, é fortemente carregada de conteúdo ideológico, de conteúdo relativo à vida. Sendo assim, o sentido é determinado pela realidade social e cultural, pelos envolvidos na interação e pelos efeitos que esse dito causa nas pessoas e na sociedade, sendo produzido e renovado a cada interação. Dessa forma, percebemos que

O centro de gravidade da língua não reside na conformidade à norma da forma utilizada, mas na significação que ela adquire no contexto. [...] para o locutor o que importa é aquilo que permite que a forma linguística figure num dado contexto, aquilo que a torna um signo adequado às condições de uma situação concreta dada. (BAKHTIN; VOLOCHÍNOV, 2009, p. 96).

Se o sentido é adquirido no contexto, as ações do Ateliê são a possibilidade de colocar a língua em uso em um verdadeiro contexto de conversação. Sujeitos interagem de forma espontânea, sem preparação prévia, sobre diferentes temáticas, intercalando, em algumas vezes, diferentes línguas na busca de uma interação significativa. O foco está na interação, na possibilidade de integração de mundos e culturas por meio da conversação. A interação verbal é produto do meio social e das interações sociais, é um fenômeno social que constitui a substância da língua. Como reiteram Bakhtin e Volochínov (2009, p. 127), “A interação verbal constitui assim a realidade fundamental da língua.". A interação é o que dá concretude ao ato de dizer, justamente por se dar entre sujeitos reais, os quais se encontram sócio-historicamente situados, marcados por suas vivências e histórias de vida 
que se presentificam na interação, mas sempre como um evento único e impossível de se repetir.

A conversação nos encontros do Ateliê demonstra o verdadeiro uso da língua, pois os sujeitos interagem e mostram a concretude do seu ato de dizer com suas vivências sociais, históricas e culturais compartilhadas com os demais. E como o objetivo é promover a interação e não aprimorar os conhecimentos linguísticos específicos, a pressão e o julgamento social por "saber ou não saber" a língua são amenizados, uma vez que o que se considera importante é interagir e integrar. Sabemos que todo enunciado é socialmente dirigido, determinado pelas pressões sociais, pela força que os sistemas ideológicos, constituídos pela moral social, têm sobre nosso discurso. Em um ambiente no qual as pressões são amenizadas, a interação ganha um caráter acolhedor, onde todos se sentem mais dispostos a interagir, sem julgamento da forma como a interação acontece.

Além disso, a riqueza cultural presente nessas interações é única. O sujeito, ao produzir discurso, falando ou escrevendo, mostra em seu texto marcas de seu meio social, suas experiências em sociedade, registrando a presença de um interlocutor e seu contexto social. Assim, interagir socialmente via língua é estabelecer relações dialógicas com o contexto social e histórico, com as condições de produção e com os papéis sociais dos interactantes envolvidos, os quais, nesta experiência aqui relatada, representam os sujeitos atuantes no Ateliê.

O convívio no Ateliê de Conversação traz a possibilidade de compartilhamento de diferentes pontos de vista, estabelecendo inúmeras relações dialógicas entre alunos e professores da Universidade de Passo Fundo com pessoas de diferentes lugares do mundo, com vivências e experiências que ampliam o horizonte social dos interactantes. De acordo com Sobral (2009, p. 44):

A interação nos termos do Círculo é condicionada pela situação pessoal, social e histórica dos participantes e pelas condições materiais e institucionais - imediatas e mediatas - em que ocorre o intercâmbio verbal. Todos esses elementos condicionam o discurso, tanto por meio da interdiscursividade [...] como por meio da relação dialógica entre os sujeitos do discurso.

O discurso é condicionado pelo contexto, ele alcança a plenitude do sentido quando relacionado à arena de ideologia e as forças sociais. A palavra varia conforme o interlocutor e o seu contexto, se esse for "uma pessoa do mesmo grupo social ou não, se esta for inferior ou superior na hierarquia social, se estiver ligada ao locutor por traços sociais mais ou menos estreitos." (BAKHTIN; VOLOCHÍNOV, 2009, p. 271). Levar em conta o interlocutor torna a interação primordial, uma propriedade constituinte da linguagem. A interação, por meio da língua, acontece nessa alternância de sujeitos, nessa relação entre os interlocutores, ao mesmo tempo falantes e ouvintes.

Assumir os imigrantes como falantes e ouvintes é fazer da linguagem uma possibilidade de integração social. É um direito de todo sujeito expressar-se e ser ouvido, além de poder ouvir e compreender o que ouve. Dar voz aos imigrantes, mesmo que em encontros singelos de conversação, é possibilitar que se constituam como sujeitos também em uma terra estrangeira. Afinal, não são apenas viajantes que estão neste país de passagem, mas indivíduos que desejam criar raízes e estabelecer-se como cidadãos 
brasileiros, desfrutando, portanto, de todo e qualquer direito e dever de um cidadão brasileiro, participando ativamente da sociedade em que vive.

Nesse sentido, considerando que o conceito de cidadania envolve ser parte de uma grande engrenagem, com todas as suas partes interligadas, assim como é uma sociedade, em que todas as nossas ações refletem no todo, é imprescindível que estes "novos" cidadãos sejam bem recebidos e acolhidos. É a partir desta perspectiva que este projeto se define como extensão.

Como já dito anteriormente, o enunciado é envolvido pelo contexto, e somente nesse contexto que ele "adquire o seu sentido pleno em determinadas condições concretas de comunicação discursiva.” (BAKHTIN, 2011, p. 288). Dessa forma, não conseguimos obter o sentido do enunciado isolado e visto apenas como forma gramatical, pois possui um significado abstrato. Só na situação concreta percebemos a expressão da posição do falante. Nessa rede de enunciações, a interação é primordial.

Como a teoria dialógica proposta pelo Círculo advém das influências do contexto social no discurso, convém lembrar que as escolhas linguísticas são condicionadas e determinadas pelo ponto de vista social. Volochínov (2013, p. 169) afirma que "a orientação social é uma das forças vivas organizadoras que, junto com a situação da enunciação, constituem não só a forma estilística, mas também a estrutura puramente gramatical da enunciação". O Ateliê, por promover essa troca sociocultural, auxilia os imigrantes na conscientização dos sentidos e das relações dialógicas que interferem na escolha da materialidade linguística. Para um estrangeiro, é muito difícil compreender porque os elementos linguísticos que usamos nas interações são "esses" e não "aqueles". Uma experiência de uso real da língua, com interlocutores dispostos a explicar as condições sociais que interferem na situação interacional, possibilita um maior entendimento sociocultural do uso da língua portuguesa aos imigrantes.

Todo discurso, portanto, emerge de uma situação de interação, de uma orientação social, de sujeitos sociais e históricos participantes. Chegamos à conclusão de que, para trabalhar com o uso da língua, em uma linha bakhtiniana, tal qual almejamos, antes, é necessário analisar o contexto social, histórico e cultural em que os indivíduos se encontram. Então, faz-se necessária a discussão sobre o meio social e o perfil dos imigrantes que fazem parte do projeto aqui apresentado.

\section{DINÂMICA MIGRATÓRIA ATUAL EM PASSO FUNDO/RS}

O processo migratório não é um fenômeno novo. Porém, na atualidade, ele está se configurando de maneiras diferentes, o que fez com que o tema das migrações internacionais tenha ganhando novos espaços nos meios acadêmicos. Diferente dos estudos históricos dos grandes processos de migração do passado, as pesquisas atuais tem um foco em outros casos de migração, como a relação entre México e EUA, o norte do continente Africano em direção à Itália e a onda revolucionária do campo político na Tunísia, Egito, Líbia e Síria. Além disso, um movimento tem chamado atenção atualmente: o novo fluxo de imigrantes no Brasil. O Brasil sempre foi considerado um país de imigrantes por excelência, mas novas perspectivas começam a fazer parte do quadro dos imigrantes no interior do país. 
Esse tema transcende as áreas, pois envolve inúmeros aspectos, tanto políticos quanto culturais, como ressalta Tedesco e Grzybovski (2011, p. 337):

O fenômeno migratório deve ser visto como um "fato social" amplo, "totalizante" do mundo atual, de experiências humanas de mudanças sociais (aspirações, emancipações) que refletem múltiplas relações, dimensões políticas, religiosas e identitárias de ambas as sociedades envolvidas. É uma dinâmica que não possui um só vetor e nem um só espaço e tempo; alimenta-se por múltiplos processos do mundo contemporâneo.

Por ser um fato social tão multifacetado, cabe aqui delimitar nosso olhar para esse fenômeno. Não nos ocupamos da dinâmica migratória em si, pois nossas pesquisas abordam a relação que os imigrantes possuem com a língua do país que os acolhe e as interações com os moradores locais. Dessa forma, o aspecto discutido é uso da língua em interação. Mesmo assim, necessitamos observar um pouco do contexto social e cultural dos envolvidos na interação, pois isso é fundamental para a discussão sobre a proposta do Ateliê de Conversação.

Até 2010, o Brasil ainda apresentava um perfil de imigração voltado aos países vizinhos, da América Latina. Conforme os estudos de Uebel (2015), a partir de 2010, inseriram-se novos grupos. Para contextualizar esse processo específico, trazemos as pesquisas realizadas por Uebel (2016), publicadas no Boletim Geográfico do Rio Grande do Sul, que trata da imigração, principalmente a Senegalesa, no Rio Grande do Sul, no início do Século XXI.

Os municípios de Caxias do Sul e Passo Fundo apresentam-se como os polos de atração e concentração imediata de imigrantes, com outros municípios próximos com concentrações de grupos pequenos. Atentando para a área do município de Passo Fundo (englobando as cidades de Não-Me-Toque, Marau, Tapejara, Getúlio Vargas e Erechim), Uebel (2016) aponta o fator do mercado de trabalho como decisivo para a escolha dessa região pelos imigrantes. A atuação laboral dos imigrantes é, majoritariamente, em empresas agroindustriais, relacionados à agricultura e pecuária. A pesquisa aponta também o fato de atuarem no comércio informal - e irregular - de produtos como relógios, bijuterias, acessórios, etc. Porém, em comparação a outras regiões, a região de Passo Fundo registra a maioria dos imigrantes com trabalho regular.

Uma informação importante, nas pesquisas realizadas com os imigrantes senegaleses, é o motivo principal da imigração: “jamais foi uma perseguição política ou guerra, mas sim as condições econômicas, já que, no país que lhes acolheu, podem receber até dez vezes mais o que recebiam no Senegal." (UEBEL, 2016, p. 70). Esse pode ser um dos motivos dos senegaleses imigrarem sozinhos, sem familiares. Além disso, a pesquisa ainda quebra a ideia de senso comum de que os imigrantes são "não letrados", mostrando que eles possuem ensino primário/secundário, muitos com cursos técnicos e/ou profissionalizantes e até ensino superior.

Para além dos dados demográfico-sociais, alguns pesquisadores se interessaram em investigar a dinâmica social dos imigrantes em Passo Fundo. Trazemos aqui alguns dados da pesquisa de Tedesco e Grzybovski (2011; 2013), da Universidade de Passo Fundo, que ressaltam aspectos do cotidiano, organização de vida, processos integrativos sociais e 
culturais dos imigrantes em Passo Fundo. As pesquisas empíricas desses autores, realizada com entrevistas individuais e coletivas, questionários e conversas informais nas ruas da cidade, é uma das únicas já realizadas oficialmente na região, devido a grande dificuldade de coleta de dados. Conforme relato dos pesquisadores, os imigrantes eram desconfiados diante dos objetivos da pesquisa e não tinham entendimento do idioma. Os autores ressaltam: "Buscamos, ainda assim, construir um 'quadro mínimo' que, acreditamos, nos deu condições de visibilidade de aspectos que constituem seu cotidiano nessa região." (TEDESCO; GRZYBOVSKI, 2011, p. 342). Notamos nesse aspecto um fator motivador para o trabalho realizado no Ateliê de Conversação aqui apresentado, que possibilita maior interação dos imigrantes com o contexto acadêmico de pesquisa.

Antes de passar para os critérios linguísticos observados, vale ressaltar ainda alguns aspectos sociais percebidos na pesquisa de Tedesco e Grzybovski (2011; 2013). A maioria revela satisfação pelo trabalho, mas diferentemente dos dados apresentados pela pesquisa demográfico-social do Boletim Geográfico do Rio Grande do Sul, a pesquisa mais intimista, com questionários e entrevistas, realizada por Tedesco e Grzybovski (2011, p. 345), mostra que "Os entrevistados, de forma unânime, manifestam não se sentirem integrados na comunidade regional fora do âmbito pragmático do trabalho. Sentem, sim, o estranhamento mesclado com curiosidade pelos que os cercam e os veem.”.

Esse estranhamento marca grande parte das interações entre senegaleses e brasileiros. Os pesquisadores ainda reforçam que existe um pensamento da população brasileira que visualiza o imigrante como "alguém que veio para trabalhar", unicamente. Ou pior, que veio para tirar o trabalho dos brasileiros. Além de tudo isso, o imigrante ainda enfrenta a discriminação por, na sua grande maioria, ser negro e de religião muçulmana. Visões assim geram situações, muitas vezes, precárias de vida e de relações de trabalho. A desqualificação e os estereótipos negativos que são produzidos tendem a fortalecer a ideia do intruso (RAMOS, 2003), fazendo com que os imigrantes sejam mais explorados em relação a outros trabalhadores de atividades similares.

Foi buscando a quebra de muitos desses estereótipos que nosso grupo de pesquisa, em Processos de Interação em Discursos de Caráter Conversacional, resolveu buscar um ponto de diálogo, contato, interação entre essas culturas diferentes. E, como relatado nas pesquisas, "O idioma é um grande empecilho para os processos integrativos e interculturais no âmbito do trabalho e no convívio social.” (TEDESCO; GRZYBOVSKI, 2011, p. 342), de modo que se anunciava a necessidade de um trabalho com língua e interação. Levando em conta que barreira linguística é um fator que gera ainda mais a ausência de contato com a comunidade, produzindo mais distanciamento e indiferença, a alternativa proposta no projeto aqui apresentado é investir em uma pesquisa-ação em um formato mais dinâmico e confortável, tanto para brasileiros quanto para imigrantes. Chegou-se então às experiências vivenciadas em forma de ateliê, já aplicadas em outras experiências de interação semelhantes e com resultados muito construtivos. Ocupamo-nos na próxima seção de apresentar essa metodologia e também nosso projeto.

\section{A LÍNGUA VIVA NO ATELIÊ DE CONVERSAÇÃo}


O curso de Letras e o Programa de Pós-Graduação em Letras (PPGL) da Universidade de Passo Fundo realizam mensalmente encontros para contatos, sociais e linguísticos, no intitulado Ateliê de Conversação. $\mathrm{Na}$ busca de uma interação realmente significativa com os imigrantes na cidade, esse projeto propõe ações sistemáticas que buscam promover encontros de interação conversacional entre imigrantes que chegam à cidade de Passo Fundo e alunos e professores dos Cursos de Letras. Inspiradas nos Ateliers de Conversation franceses retratados no documentário de Bernhard Braunstein, as atividades buscam unicamente um processo interacional multilíngue e multicanal, no qual concorrem para o estabelecimento de sentido as construções linguísticas em português, francês, inglês, espanhol, línguas africanas e crioulas, gestualidades e os olhares. Devido ao conhecimento de diferentes línguas, tanto por parte dos alunos e professores do Curso de Letras, quanto por parte dos imigrantes, as trocas conversacionais são um exemplo vivo da diversidade linguística que um processo de imigração resulta.

Já que, nesses encontros, ninguém é considerado “estrangeiro", mas sujeitos dispostos a interagir em diferentes línguas, sobre diferentes assuntos, o objetivo é socializar experiências pessoais por meio da língua viva, em interação. É importante frisar que as ações do projeto não visam ensinar formalmente língua alguma, mas propiciar, de fato, a interação humana, condição para a vida em sociedade. É justamente o formato de Ateliê que possibilita essa interação em diferentes línguas de maneira mais confortável, sem medo de julgamento. É sobre esse formato que discutimos na seção a seguir.

\subsection{INTERAÇÃO EM FORMA DE ATELIÊ DE CONVERSAÇÃO}

A metodologia definidora da prática do Ateliê é pautada em outras experiências de interação semelhantes já realizadas envolvendo imigrantes, em especial, naquelas retratadas no documentário francês Atelier de conversation (2018) do alemão Bernhard Braustein. O documentário retrata os encontros de um grupo de estrangeiros, residentes da cidade de Paris, que se encontram semanalmente, debatem temas diversos e compartilham dois objetivos em comum: "aprender a língua e encontrar aliados e amigos para poder (sobre) viver no exterior" (ATELIER, 2018, p. 3, tradução livre dos autores).

O idealizador e produtor Braustein, sendo ele próprio um alemão que decidiu mudar de vida e mudou-se para Paris, encontrou como maior obstáculo de inserção na sociedade francesa a língua, não encontrando solução em cursos intensivos de língua, os quais, segundo ele, são pautados na gramática, e acabam deixando a prática de lado. Em busca de uma solução, o alemão encontrou o grupo de ateliê na biblioteca pública de informação da capital francesa e começou a frequentá-lo.

Segundo ele, o ateliê é "um lugar de esperança, uma divagação humana, um parêntese, uma interrupção da luta cotidiana por sobrevivência. É um ponto de encontro tolerante e isento de hierarquia, uma mistura de numerosas realidades da vida de uma grande cidade" (ATELIER, 2018, p. 4, tradução livre dos autores). Nos encontros retratados no documentário, não há correções de erros gramaticais, tendo em vista que se trata de um espaço de experiência humana, cercado de trocas, em que cada membro pode propor livremente temas para discussão, deixando de lado qualquer diferença de crença, visão política e religiosa. 
O ateliê de conversação permite o contraste e o choque de diferentes mundos e, consequentemente, o encontro de diferentes histórias, "maneiras de cooperar e interagir, de escutar e falar, de se compreender e mal compreender, de se encontrar e de sorrir" (ATELIER, 2018, p. 4, tradução livre dos autores).

De posse dessa experiência francesa, mesmo que a distância, e considerando o grande número de imigrantes que residem na cidade de Passo Fundo, o projeto Ateliê de Conversação, inspirado na versão francesa, também procura contribuir para a inserção dos indivíduos imigrantes na comunidade passofundense, dando-lhes espaço para expressarem suas experiências e inquietudes.

Ao contrário do projeto francófono, as trocas deste ateliê ocorrem entre nativos e recém-chegados à cidade, favorecendo o estabelecimento de novas conexões e relações humanas. Trata-se, portanto, de um espaço com disparidades culturais e sociais, mas que também partilha dois fins comuns: a prática da língua viva e o sentimento de pertencimento à cidade. Para tanto, alguns princípios metodológicos são seguidos, tendo em vista o caráter dialógico e social de todo o processo. Entre esses princípios, destacamos dois.

O primeiro deles diz respeito à própria concepção dialógica do processo interacional, segundo a qual todos os sujeitos interactantes têm o mesmo direito de participação, na busca de se realizar um diálogo em que as trocas de turnos e de informações sejam simétricas. Esse fator que garante a participação de todos e torna a interação realmente dialógica, pois "A vida é dialógica por natureza. Viver significa participar de um diálogo.” (BAKHTIN, 2011, p.293). Sendo assim, a interação no Ateliê abre o espaço para a voz do outro e afasta o tipo de interação dos modelos préestabelecidos, como a sistemática tradicional de salas de aulas, na qual, em geral, a participação é assimétrica, uma vez que cabe ao professor, na maioria das vezes, a condução do processo. Além disso, o princípio dialógico de interação e, principalmente, o próprio conceito de conversação, não autoriza a definição prévia de formatos interacionais, os quais se definem na realização mesma da conversação, na vivência do que entendemos ser a imprevisibilidade pragmática, condutora das escolhas de cada interactante, as quais revelam um trabalho colaborativo. Dar voz ao outro, deixar que o outro tenha a possibilidade de escolher os caminhos da interação assim como você é torná-lo sujeito, tornar cada um dos indivíduos do grupo de interação um sujeito histórico e ideológico.

O segundo princípio metodológico diz respeito à compreensão das interações conversacionais como realidades multicanais e plurissemióticas. Kerbrat-Orecchioni (1986) lembra que a interação se caracteriza pela mobilização de signos linguísticos e não linguísticos; logo, a interação é promovida, certamente, pela mobilização de expressões linguísticas organizadas de forma discursiva, mas as quais também são constituídas, muitas vezes, também pelas gestualidades, pelos olhares, pelo toque de mãos, pelos gestos de acolhida, como o abraço de boas-vindas, por exemplo. Além dessa realidade, este segundo princípio se revela potencial no uso de ferramentas tecnológicas, como o aparelho celular, o qual permite que se complemente o dizer com consultas a tradutores digitais, ou mesmo, com a exemplificação de um evento da conversação por meio de um vídeo na plataforma youtube. 
Esses princípios metodológicos são norteadores nas ações do Ateliê que ocorrem na Universidade de Passo Fundo. A dinâmica nos encontros, pautada nesses princípios e formato, serão apresentados na seção seguinte.

\subsection{OS ENCONTROS NO ATELIÊ DE CONVERSAÇÃO PARA IMIGRANTES}

As ações do Ateliê de Conversação ainda se encontram em andamento. Seu início, no segundo semestre de 2019, proporcionou vários encontros e o que foi realizado até aqui já nos dá um panorama do potencial do projeto e resultados obtidos. Os primeiros encontros foram uma espécie de princípio de interação, com poucos imigrantes, em espaços públicos, como uma cafeteria, por exemplo, na busca de se travarem as primeiras relações. Nesses encontros, os imigrantes participantes eram estudantes de escola pública de Ensino Médio da cidade e manifestaram seu interesse em conhecer outros espaços e outras pessoas, para além da escola. Buscavam quem pudesse mostrar mais sobre a cidade e as possíveis condições de oferta de trabalho e de estudo para eles, uma vez que gostariam de se sentir mais integrados com a cidade, já que, como eles mesmos afirmaram, "somos cidadãos passofundenses agora".

Foi justamente a manifestação desse desejo que levou à promoção dos demais encontros, os quais se realizam com frequência mensal, no Centro de Referência de Literatura e Multimeios - Mundo da Leitura. Este espaço funciona como laboratório do curso de Letras e do programa de Pós-Graduação em Letras da Universidade de Passo Fundo. Nesse ambiente, os encontros do Ateliê possibilitaram a participação de mais pessoas, todas convidadas e com inserção voluntária no projeto.

A interação proposta, de maneira colaborativa, iniciou com uma atenção especial dos envolvidos para temas derivados das vivências de cada um: Quem sou eu e qual minha história? Qual minha relação com a cidade de Passo Fundo? Que aspectos culturais da cidade e do estado do Rio Grande do Sul eu me interesso? O que gosto ou não na cidade? Quais os desafios diários que enfrentamos? A partir dessas interações, que aconteceram em diferentes línguas, conforme cada sujeito se sentia a vontade de interagir, o contato foi aprimorado e aos poucos, conhecimentos linguísticos e conhecimentos de mundo foram sendo compartilhados.

Enquanto professores e alunos, brasileiros e falantes nativos de português, conseguiam praticar e vivenciar as línguas "estrangeiras" de maneira natural, com falantes daquelas línguas, os imigrantes tinha a oportunidade de trocar experiências usando a língua portuguesa, que agora tornou-se a língua que ele mais precisava conhecer para usar no seu cotidiano. Esse contato linguístico e troca de conhecimentos, sem a rigorosidade das aulas de língua estrangeira, possibilitou não só o aprofundamento dos conhecimentos linguísticos, como também uma troca de vivências e de pontos de vista única. Indivíduos de lugares, crenças, ideologias e padrões de vida diferentes interagindo e conhecendo melhor uns aos outros, tudo isso mediado pela língua em uso, pela linguagem, pelo discurso.

Os encontros iniciais possibilitaram troca de contatos, que resultaram em novos encontros, alguns de caráter mais particular, realizados entre os "novos amigos" constituídos no Ateliê. Aqueles que eram considerados estrangeiros passam a ser 
conhecidos do grupo, com nomes e referências. Além disso, novos encontros em grupo foram marcados, muitos para interação livre, outros com temáticas específicas, como por exemplo, encontro para falar sobre as músicas de diferentes lugares no mundo, encontro sobre o tradicionalismo gaúcho, entre outros.

A ação ainda acontece no período letivo da Universidade de Passo Fundo. E novas ações significativas já foram propostas, como a discussão sobre línguas crioulas. Alguns imigrantes participantes são haitianos e um grupo de brasileiros demonstrou o desejo de aprender crioulo de base francesa, o idioma desses imigrantes haitianos. Sendo assim, surgiram novas ações prospectivas do Ateliê, como as oficinas de crioulo desenvolvidas por alguns haitianos, os quais se disponibilizaram a fazê-las. Sem dúvida, está implicado nesta decisão um olhar para o lugar do outro, o que só é possível em função do reconhecimento do seu próprio lugar de existência no mundo.

Para finalizar, gostaríamos de enfatizar dois aspectos que nos fazem perceber os resultados do projeto Ateliê de Conversação para imigrantes. O primeiro, diz respeito ao aprimoramento dos estudantes e professores do Curso de Letras e também dos demais participantes brasileiros, falantes de português, que veem os encontros do Ateliê como um verdadeiro processo de imersão em novas línguas. O aprendizado de uma língua estrangeira enriquece-se, em diversos aspectos, com os encontros multilíngues, como os que acontecem no Ateliê. Além de aprimorar o domínio da língua estrangeira, ainda existe a possibilidade de conhecer novos pontos de vista, diferentes culturas e crenças, conhecer o diferente e quebrar preconceitos por não conhecer o "outro" que está tão perto, como são os imigrantes.

Já o segundo aspecto diz respeito à possibilidade de os imigrantes terem contato e praticarem o uso da língua portuguesa sem julgamentos por "falar errado". Muitos depoimentos dos imigrantes que participam do projeto mostram que eles têm vergonha de falar português com brasileiros, pois acreditam que não sabem o suficiente. Então, privam-se de falar, dizem somente o necessário e nas suas interações mais íntimas e familiares, preferem continuar falando suas línguas maternas. Assim, o Ateliê, para muitos, era o único lugar em que podiam falar português sem preocupação, e ainda mais, tirar suas dúvidas sem receio.

Além desses aspectos linguísticos, o grande ganho do processo de contato com a diversidade linguística é a partilha de diferentes vivências interacionais verdadeiramente significativas para todos os envolvidos. Entre bate-papos informais e conversas aparentemente despretensiosas, há a inserção do sujeito num grupo social, formado por pessoas que partilham determinados interesses e compartilham vivências. Isso tudo só é possível em função da linguagem e da (s) língua (s) em interação. É esta experiência que promove o que entendemos como conhecer o outro por meio da língua viva em interação, o que é condição para a vida digna em sociedade.

\section{CONSIDERAÇÕES FINAIS}

As ações do Ateliê demonstram uma possibilidade interessante de trabalho com a diversidade linguística em sua relação com políticas linguísticas. Além disso, o contato linguístico decorrente dos encontros do Ateliê de Conversação para imigrantes possibilita 
a troca significativa de experiências de vida por meio da língua. Sendo uma ação vinculada ao Programa de Extensão da Universidade de Passo Fundo, sua realização, contribuem, também, para os estudos acerca do tema interação, realizados por grupos de pesquisa do PPGL, em especial, os vinculados à linha de pesquisa Constituição e Interpretação do Texto e do Discurso, envolvendo um olhar acadêmico para o texto e o discurso.

É importante destacar que o projeto já tem contato com empresas da região que veem no imigrante possibilidade de mão de obra para seus empreendimentos e acabam por empregar um grande número de haitianos e venezuelanos, principalmente. O objetivo do projeto, junto a essas empresas, é desenvolver outros Ateliês de Conversação, com o apoio da empregadora. No entanto, esta aproximação é lenta e envolve interesses distintos das partes, o que não permite ainda que se pense nos resultados de tal ação específica.

Por ora, é possível afirmar que, por meio de uma estrutura teórica desenvolvida pela equipe de professores junto aos estudantes envolvidos, as ações do projeto consolidam uma verdadeira ação comunitária sobre o processo de imigração na cidade. Já que a imigração, na maioria das vezes, gera um conflito na interação, o que dificulta a integração dos imigrantes na nova sociedade, as ações do Ateliê de Conversação buscam não só auxiliar no aprimoramento linguístico dos imigrantes, mas também de integrá-los por meio da interação verbal na sociedade passofundense.

\section{REFERÊNCIAS}

ATELIER de conversation. Direção de Bernhard Braunstein. Paris: ASC Distribuition, 2018. (74min).

BAKHTIN, M. M. Estética da criação verbal. Trad. Paulo Bezerra. 6. ed. São Paulo: Editora WMF Martins Flores, 2011.

BAKHTIN, M. M.; VOLOCHÍNOV, V. N. Marxismo e filosofia da linguagem. Trad. Michel Lahud e Yara Frateschi Vieira. 13. ed. São Paulo: Hucitec, 2009.

KERBRAT- ORECCHIONI, C. «Nouvelle communication» et «analyse conversationnelle». Langue française, n70, p. 7-25, 1986. Disponível em: < http://www.persee.fr/doc/lfr 0023-8368 1986 num 701 6368 >. Acesso em: 20 jan. 2020.

RAMOS, P. S. Hospitalidade e migrações internacionais: o bem receber e o ser bem recebido. São Paulo: Aleph, 2003.

SOBRAL, A. Dialogismo e interação. In: SOBRAL, A. Do dialogismo ao gênero: as bases do pensamento do círculo de Bakhtin. Campinas, SP: Mercado de Letras, 2009, p. 21-46.

TEDESCO, J. C.; GRZYBOVSKI, D. Senegaleses no norte do Rio Grande do Sul: integração cultural, trabalho e dinâmica migratória internacional. Revista Espaço Pedagógico, 
Passo Fundo, v. 18, n. 2, p. 336-355, jul./dez. 2011. Disponível em: < http://seer.upf.br/index.php/rep/article/view/2433 >. Acesso em: 20 jan. 2020.

UEBEL, R. R. G. Análise do perfil socioespacial das migrações internacionais para o Rio Grande do Sul no início do século XXI. 2015. 248 f. Dissertação (Mestrado) - Programa de PósGraduação em Geografia, Universidade Federal do Rio Grande do Sul, Porto Alegre, 2015.

UEBEL, R. R. G. Panorama e perfil da imigração senegalesa no Rio Grande do Sul no início do século XXI. Boletim Geográfico do Rio Grande do Sul, Porto Alegre, n. 28, p. 56-77, set. 2016. Disponível em: < https://revistas.fee.tche.br/index.php/boletim-geograficors/article/view/3731 >. Acesso em: 20 jan. 2020.

VOLOCHÍNOV, V. N. Estrutura do Enunciado. Tradução de Ana Vaz. In: TODOROV, T. Mikhail Bakhtin: le príncipe dialogique. Paris: Seuil, 1981. p. 1-19.

VOLOCHÍNOV, V. A construção da enunciação. In: VOLOCHÍNOV, V. A construção da enunciação e outros ensaios. Tradução de João Wanderley Geraldi. São Carlos: Pedro \& João editores, 2013. p. 157-188.

Recebido em: 10/10/2019

Aprovado em: 07/12/2019

Publicado em: 30/04/2020 